\title{
A STUDY ON MATHEMATICAL AND STATISTICAL ASPECTS OF LINEAR MODELS
}

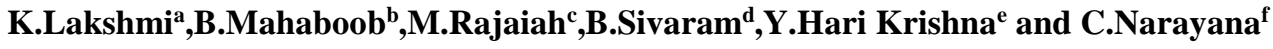 \\ ${ }^{a, b}$ Department of Mathematics, Koneru Lakshmaiah Education Foundation, Vaddeswaram,AP,India \\ ${ }^{c}$ Department of Mathematics,Audisankara College of Engineering \& Technology (Autonomous) Gudur, SPSR Nellore(Dt), \\ A.P., India \\ ${ }^{d}$ Department of Mathematics, Koneru Lakshmaiah Education Foundation, Aziznagar, Hyderabad \\ e Department of Mathematics, ANURAG Engineering College, Ananthagiri (v), Kodad,Suryapet,Telangana-508 $206 f$

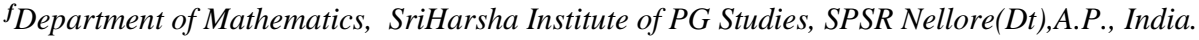

Article History: Received: 11 January 2021; Accepted: 27 February 2021; Published online: 5 April 2021

\begin{abstract}
The primary objective of this research article is to present the mathematical and statistical aspects of linear models and their characteristic properties. Linear model is the most common modeling used in science. Actually linear models have many different meanings depend on the context. Linear model is often preferred than other model such as quadratic model because of its ability to interpret easily. In the other hand most of the real life cases have linear relationship .Modeling the cases using linear model will able us to determine the relative influence of one or more independent variables to the dependent variable. In the present talk an attempt has been made to propose the specific forms of simple and multiple linear regression models. In this conversation mathematical aspects of linear models have been extensively depicted. Different types of mathematical models are discussed here and the methods of fitting transformed models are proposed.Furthermore specific form of linear statistical model is presented and the crucial assumptions of general linear model are extensively discussed.At the last stage of this article the method of ordinary least squares estimation of parameters of a linear model has been proposed

Keywords: Linear Regression Model, Response variable,Predictor,Discrete and continuous models, Biasedness,NonStochastic data matrix
\end{abstract}

\begin{abstract}
1.Introduction
Model refers to a set of functional or structural relationships between two or more characteristics. These characteristics may be either measuremental or non measuremental in nature. The measuremental characteristics which assume different values in a specified range are known as variables. Generally, a set of functional relationships between two or more variables may be expressed in terms of mathematical equations, which is called a mathematical model. This model may be either in the form of a set of linear equations (linear model) or in the form of a set of nonlinear equations (nonlinear model). By introducing a random error variable or a random disturbance term, the mathematical model becomes a statistical model or a regression model. Hence one may have either linear regression model or nonlinear regression model.

Regression analysis is a statistical method to establish the relationship between variables. Regression analysis has a wide number of applications in almost all fields of science, including Engineering, Physical and Chemical Sciences; Economics, Management, Social, Life and Biological Sciences. In fact, regression analysis may be the most frequently used statistical technique in practice.
\end{abstract}

Suppose that there exists a linear relationship between a dependent variable $\mathrm{Y}$ and an independent variable $\mathrm{X}$. In the scatter diagram, if the points cluster around a straight line then the mathematical form of the linear model may be specified as

$\mathrm{Y}_{\mathrm{i}}=\beta_{0}+\beta_{1} \mathrm{X}_{\mathrm{i}}, \mathrm{i}=1,2, \ldots \mathrm{n}$.

where $\beta_{0}$ is the intercept and $\beta_{1}$ is the slope.

Generally the data points in the scatter diagram do not fall exactly on a straight line, so equation (2.1.1) should be modified to account for this. Let the difference between the observed value of $\mathrm{Y}$ and the straight line $\left(\beta_{0}+\beta_{1} \mathrm{X}\right)$ be an error $\varepsilon$. It is convenient to think of $\varepsilon$ as a statistical error; that is, it is a random variable that accounts for the failure of the model to fit the data exactly. The error may be made up of the effects of other variables, measurement errors and so forth. Thus, a more plausible model may be specified as

$\mathrm{Y}_{\mathrm{i}}=\beta_{0}+\beta_{1} \mathrm{X}_{\mathrm{i}}+\varepsilon_{\mathrm{i}}, \mathrm{i}=1,2, \ldots, \mathrm{n}$.

Equation (2) is called a Linear Regression Model or Linear Statistical Model. Customarily X is called the independent variable and $\mathrm{Y}$ is called the dependent variable. However, this often causes confusion with the concept of statistical independence, so we refer to $\mathrm{X}$ as the Predictor or Regressor variable and $\mathrm{Y}$ as the Response variable. Since the equation (1) involves only one Regressor variable, it is called a 'Simple Linear Regression Model' or a 'Two-Variable Linear Regression Model'. 
A Three - variable Linear Regression Model may be written as $\mathrm{Y}_{\mathrm{i}}=\beta_{0}+\beta_{1} \mathrm{X}_{1 \mathrm{i}}+\beta_{2} \mathrm{X}_{2 \mathrm{i}}+\varepsilon_{\mathrm{i}}, \mathrm{i}=1,2, \ldots, \mathrm{n}$

This linear regression model contains two regressor variables. The term linear is used because eq. (2.1.3) is a linear function of the unknown parameters $\beta_{0}, \beta_{1}$ and $\beta_{2}$.

In general, the response variable $\mathrm{Y}$ may be related to $\mathrm{k}$ regressor or predictor variables. The model

$\mathrm{Y}_{\mathrm{i}}=\beta_{0}+\beta_{1} \mathrm{X}_{1 \mathrm{i}}+\beta_{2} \mathrm{X}_{2 \mathrm{i}}+\ldots+\beta_{\mathrm{k}} \mathrm{X}_{\mathrm{ki}}+\varepsilon_{\mathrm{i}}, \mathrm{i}=1,2, \ldots \mathrm{n}$

is called a 'Multiple Linear Regression Model' with $\mathrm{k}$ independent variables. The parameters $\beta_{\mathrm{j}}, \mathrm{j}=0,1,2$..,k are known as regression coefficients. This model describes a hyperplane in the $\mathrm{k}$ - dimensional space of the independent variables $\mathrm{X}_{\mathrm{j}}$ 's. The parameter $\beta_{\mathrm{j}}$ represents the expected change in the dependent variable $\mathrm{Y}$ per unit change in $X_{j}$, when all of the remaining predicted variables $X_{q}$ 's $(q \neq j)$ are held constant. Thus, the parameters $\beta_{j}$, $\mathrm{j}=1,2, \ldots, \mathrm{k}$ are often known as 'Partial Regression Coefficients.

Multiple linear regression models are often used as empirical models or approximating functions. That is, the exact relationship between $\mathrm{Y}$ and $\mathrm{X}_{1}, \mathrm{X}_{2}, \ldots, \mathrm{X}_{\mathrm{k}}$ is unknown but over certain ranges of the independent variables, the linear regression model is an adequate approximation to the true unknown function.

In practice, certain nonlinear regression models such as cubic polynomial models and response surface models may often still be analyzed by multiple linear regression techniques. For instance, consider the cubic polynomial model

$\mathrm{Y}_{\mathrm{i}}=\beta_{0}+\beta_{1} \mathrm{X}_{\mathrm{i}}+\beta_{2} \mathrm{X}_{\mathrm{i}}^{2}+\beta_{3} \mathrm{X}_{\mathrm{i}}^{3}+\varepsilon_{\mathrm{i}}, \mathrm{i}=1,2, \ldots, \mathrm{n}$

Let $\mathrm{X}_{1}=\mathrm{X}, \mathrm{X}_{2}=\mathrm{X}^{2}$ and $\mathrm{X}_{3}=\mathrm{X}^{3}$ then eq. (5) can be rewritten as

$\mathrm{Y}_{\mathrm{i}}=\beta_{0}+\beta_{1} \mathrm{X}_{1 \mathrm{i}}+\beta_{2} \mathrm{X}_{2 \mathrm{i}}+\beta_{3} \mathrm{X}_{3 \mathrm{i}}+\varepsilon_{\mathrm{i}}, \mathrm{i}=1,2, \ldots, \mathrm{n}$

which is a multiple linear regression model with three independent variables

Consider a model containing interaction effects as

$\mathrm{Y}_{\mathrm{i}}=\beta_{0}+\beta_{1} \mathrm{X}_{1 \mathrm{i}}+\beta_{2} \mathrm{X}_{2 \mathrm{i}}+\beta_{12} \mathrm{X}_{1 \mathrm{i}} \mathrm{X}_{2 \mathrm{i}}+\varepsilon_{\mathrm{i}}, \mathrm{i}=1,2, \ldots, \mathrm{n}$

Let $X_{3}=X_{1} X_{2}$ and $\beta_{3}=\beta_{12}$ then eq (7) can be rewritten as

$\mathrm{Y}_{\mathrm{i}}=\beta_{0}+\beta_{1} \mathrm{X}_{1 \mathrm{i}}+\beta_{2} \mathrm{X}_{2 \mathrm{i}}+\beta_{3} \mathrm{X}_{3 \mathrm{i}}+\varepsilon_{\mathrm{i}}, \mathrm{i}=1,2, \ldots, \mathrm{n}$

which is a multiple linear regression model with three regressors. Consider the second - order response surface model with interaction,

$\mathrm{Y}_{\mathrm{i}}=\beta_{0}+\beta_{1} \mathrm{X}_{1 \mathrm{i}}+\beta_{2} \mathrm{X}_{2 \mathrm{i}}+\beta_{11} \mathrm{X}_{1 \mathrm{i}}^{2}+\beta_{22} \mathrm{X}_{2 \mathrm{i}}^{2}+\beta_{12} \mathrm{X}_{1 \mathrm{i}} \mathrm{X}_{2 \mathrm{i}}+\varepsilon_{\mathrm{i}}, \mathrm{i}=1,2, \ldots, \mathrm{n}$

Let $\mathrm{X}_{3}=\mathrm{X}_{1}^{2}, \mathrm{X}_{4}=\mathrm{X}_{2}^{2}, \mathrm{X}_{5}=\mathrm{X}_{1} \mathrm{X}_{2}, \beta_{3}=\beta_{11}, \beta_{4}=\beta_{22}$ and $\beta_{5}=\beta_{12}$ then eq. (2.1.9) can be rewritten as a multiple linear regression model as follows:

$\mathrm{Y}_{\mathrm{i}}=\beta_{0}+\beta_{1} \mathrm{X}_{1 \mathrm{i}}+\beta_{2} \mathrm{X}_{2 \mathrm{i}}+\beta_{3} \mathrm{X}_{3 \mathrm{i}}+\beta_{4} \mathrm{X}_{4 \mathrm{i}}+\beta_{5} \mathrm{X}_{5 \mathrm{i}}+\varepsilon_{\mathrm{i}}, \mathrm{i}=1,2, \ldots, \mathrm{n}$

\section{MATHEMATICAL ASPECTS OF LINEAR MODEL}

The main purpose of mathematical modelling is to solve real practical problems. The success of mathematical modelling depends on getting things right from the start, and as in most other scientific endeavours, one is more likely to succeed if one adopts a methodical approach. In practice, it is found to complete the following steps.

(i) Clarify the problem;

(ii) List the factors;

(iii) List the assumptions; and

(iv) Formulate a precise problem statement

An essential part of the mathematical modelling technique is to translate verbal statements about variables along with assumptions into precise mathematical relationships between the variables represented by symbols. Thus, the mathematical statements become amenable to manipulation by mathematical techniques.

For instance, the simplest model is obtained by assuming that $\mathrm{Y}$ is proportional to $\mathrm{X}$. The corresponding mathematical statement is then $\mathrm{Y} \propto \mathrm{X}$ or as a mathematical equation $\mathrm{Y}=\beta_{0} \mathrm{X}$, where $\beta_{0}$ is the constant of proportionality. Now, the graph of $\mathrm{Y}$ against $\mathrm{X}$ shows a straight line through the origin. 
Another simplest model is the linear form $\mathrm{Y}=\beta_{0}+\beta_{1} \mathrm{X}$ in which $\mathrm{Y}$ increases by $\beta_{1}$ units for every unit increase in $\mathrm{X}$ and that $\mathrm{Y}=\beta_{0}$ when $\mathrm{X}=0$. This also includes the situation where $\mathrm{Y}$ decreases as $\mathrm{X}$ increases. In that situation the parameter $\beta_{1}$ is negative.

Consider the situation where ' $\mathrm{Y}$ decreases as $\mathrm{X}$ increases' by inverse proportion

$\mathrm{Y} \propto \frac{1}{\mathrm{X}}$ or $\mathrm{Y}=\frac{\beta_{0}}{\mathrm{X}}$

It reveals that $\mathrm{Y}$ decreases more steeply with $\mathrm{X}$ that is the situation in the linear model. One may test the validity of this assumption by examining whether XY remains nearly constant. Another way is that if the plot of Ln Y against $\mathrm{Ln} \mathrm{X}$ is a straight line of slope "-1".

Thus, under mathematical modelling technique, first represent the variables by the mathematical symbols and then make the assumptions about the relationships among the variables. Further, translate the assumptions into mathematical equations or inequalities.

One of the main uses of mathematical modelling is to predict the future development of the system. Such model relies on assuming that the rate of change of a variable $\mathrm{Y}$ is linked to or caused by some or all of the present value of $Y$, previous values of $Y$, values of other variables, the rate of change of other variables and time ' $t$ '. Here, the mathematical model describes how $\mathrm{Y}$ itself varies with time ' $\mathrm{t}$ '. There are mainly two types of such mathematical models namely,

(i) Discrete Models and (ii) Continuous Models

\section{DISCRETE MODELS:}

For discrete models, one may write the form

(ii)

$\mathrm{Y}_{\mathrm{n}+1}=\mathrm{f}\left(\mathrm{Y}_{\mathrm{n}}, \mathrm{Y}_{\mathrm{n}-1} \ldots, \mathrm{t}\right)$

It is usually known as a difference equation. The simplest type of difference equation is the first order linear constant coefficient equation which is given by

$\mathrm{Y}_{\mathrm{n}+1}=\beta_{0}+\beta_{1} \mathrm{Y}_{\mathrm{n}}$

A difference equation containing relationship between $Y_{n+1}$ and $Y_{n}$ and no other $Y$ values is known as a 'First order difference equation. If the difference equation also involves $Y_{n-1}$ or $Y_{n+2}$, then it is said to be second order difference equation.

Sometimes, a linear difference equation may be in the form

$$
\mathrm{Y}_{\mathrm{n}+1}=\beta_{1} \mathrm{Y}_{\mathrm{n}}+\beta_{2} \mathrm{Y}_{\mathrm{n}-1}+\mathrm{n}^{2}+\beta_{0}
$$

Linear difference equations involving more than one variable can be compactly expressed by using vectors and matrices.

Simultaneous linear difference equations can be expressed in the form

$\overline{\mathrm{Y}}_{\mathrm{n}+1}=\overline{\mathrm{M}} \overline{\mathrm{Y}}_{\mathrm{n}}$

where $\overline{\mathrm{M}}_{\text {is the co-efficient matrix; }} \overline{\mathrm{Y}}_{\mathrm{n}+1}$ and $\overline{\mathrm{Y}}_{\mathrm{n}}$ are the vectors.

The solution can be written as
CONTINUOUS MODELS

A variable, which is allowed to take any value within a range, is known as a continuous variable. One advantage of using continuous variables is that one may use powerful mathematical tools such as Calculus.

The linear models are the simplest continuous models. The simplest linear model relating two variables is characterized by mathematical equation of the form $\mathrm{Y}=\beta_{0}+\beta_{1} \mathrm{X}$, by having a straight line graph.

Under linear interpolation, if $\mathrm{x}_{1}$ and $\mathrm{x}_{2}$ are consecutive values of $\mathrm{X}$ and $\mathrm{x}$ is some value between them, then the graph of $\mathrm{f}(\mathrm{x})$ may be approximating from $\mathrm{X}=\mathrm{x}_{1}$ to $\mathrm{X}=\mathrm{x}_{2}$ by a linear model. 


\section{TYPES OF LINEAR MATHEMATICAL MODEL Linear Models with Several Independent Variables:}

If the value of a dependent variable $Y$ depends on the values of other variables $X_{1}, X_{2}, \ldots ., X_{k}$ then a way of expressing the dependence through a linear model is of the form

$$
\mathrm{Y}_{\mathrm{i}}=\beta_{0}+\beta_{1} \mathrm{X}_{1 \mathrm{i}}+\beta_{2} \mathrm{X}_{2 \mathrm{i}}+\ldots+\beta_{\mathrm{k}} \mathrm{X}_{\mathrm{ki}}
$$

Here Y changes by equal amounts for equal changes in any one of the independent variables. This model can be considered the generalization of the simple two- variable linear model

\section{Simultaneous Linear Models:}

Sometimes there may be two or more dependent variables, all of which are modelled as linear functions of independent variables. Here, some dependent variables can be considered independent variables in some linear functions (or equations) of the simultaneous linear equations system. This system of simultaneous linear models can be solved by using matrix methods such as Cramer's Rule, Inverse Matrix method etc.

\section{Piecewise Linear Models:}

It is a model that does not have to be represented by the same single formula for all values of the independent variable $\mathrm{X}$. Here, two different linear expressions agree at some value of $\mathrm{X}$, so there is no sudden jump ( discontinuity) at the changeover point, usually $\mathrm{X}$ may be a discrete variable in this model, sometimes, one may model a non-linear function approximately by a piecewise linear function.

\section{Transformed Linear Models:}

When a dependent variable $\mathrm{Y}$ does not change by equal amounts for equal changes in the independent variable then a linear model may not be suitable for this situation. For instance, the quadratic function or a second degree parabola is a simple nonlinear model.

$$
\mathrm{Y}_{\mathrm{i}}=\beta_{0}+\beta_{1} \mathrm{X}_{\mathrm{i}}+\beta_{2} \mathrm{X}_{\mathrm{i}}^{2}, \mathrm{i}=1,2, \ldots, \mathrm{n}
$$

Three separate pieces of information are needed to determine the three parameters $\beta_{0}, \beta_{1}$ and $\beta_{2}$. The value of $\beta_{2}$ determines whether the curve is concave upwards ( $\beta_{2}>0$ ) or concave downwards, There is a vertical axis of symmetry at $\mathrm{X}=\frac{-\beta_{1}}{2 \beta_{2}}$ which is also the $\mathrm{X}$ value at which the graph has global maximum or minimum value. The value of the parameter $\beta_{0}$ affects the vertical position of the curve relative to the coordinate axes.

A more general higher degree polynomial model can be written as

$$
\mathrm{Y}_{\mathrm{i}}=\beta_{0}+\beta_{1} \mathrm{X}_{\mathrm{i}}+\beta_{2} \mathrm{X}_{\mathrm{i}}^{2}+\beta_{3} \mathrm{X}_{\mathrm{i}}^{3}+\ldots+\beta_{\mathrm{k}} \mathrm{X}_{\mathrm{i}}^{\mathrm{k}}, \mathrm{i}=1,2, \ldots \ldots, \mathrm{n}
$$

This model can be transformed into a general linear model as $\mathrm{Y}_{\mathrm{i}}=\beta_{0}+\beta_{1} \mathrm{Z}_{1 \mathrm{i}}+\beta_{2} \mathrm{Z}_{2 \mathrm{i}}+\beta_{3} \mathrm{Z}_{3 \mathrm{i}}+\ldots+\beta_{\mathrm{k}} \mathrm{Z}_{\mathrm{ki}}$

where, $\mathrm{Z}_{1}=\mathrm{X}, \mathrm{Z}_{2}=\mathrm{X}^{2}, \mathrm{Z}_{3}=\mathrm{X}^{3}, \ldots \ldots . . \mathrm{Z}_{\mathrm{k}}=\mathrm{X}^{\mathrm{k}}$

Likewise, some nonlinear models such as power function model ( $\left.\mathrm{Y}=\beta_{0} \mathrm{X}^{\beta_{1}}\right)$, Exponential Model $\left(\mathrm{Y}=\beta_{0} \mathrm{e}^{\beta_{1} \mathrm{X}}\right.$ or $\left.\mathrm{Y}=\beta_{0} \beta_{1}^{\mathrm{X}}\right)$ etc, can be transformed into logarithmic linear models $\operatorname{Ln} Y=\operatorname{Ln} \beta_{0}+\beta_{1} \operatorname{Ln} X ;$ and

$\operatorname{Ln} Y=\operatorname{Ln} \beta_{0}+\beta_{1} X$ or $\operatorname{Ln} Y=\operatorname{Ln} \beta_{0}+\left(\operatorname{Ln} \beta_{1}\right) X$ etc., respectively.

When the rate of change of $\mathrm{Y}$ is assumed to be proportional to the difference between the present value of $\mathrm{Y}$ and some fixed value $\mathrm{c}$, one may write the linear first order differential equation model as 
$\mathrm{Y}^{\prime}=\mathrm{k}(\mathrm{c}-\mathrm{Y})$, which has the solution $\mathrm{Y}(\mathrm{t})=\mathrm{c}+\left(\mathrm{Y}_{0}-\mathrm{c}\right) \mathrm{e}^{-\mathrm{kt}}$

with $\mathrm{Y} \rightarrow \mathrm{c}$ as $\mathrm{t} \rightarrow \infty$.

\section{FITTING OF TRANSFORMED LINEAR MODELS}

In fitting of time series models or Growth curves to the time series data, the following points may be useful to specify the type of the model:

(i) When the time series $\mathrm{Y}_{\mathrm{t}}$ is formed to be increasing or decreasing by equal absolute amounts, the straight line times series model is used.

$\mathrm{Y}_{\mathrm{t}}=\beta_{0}+\beta_{1} \mathrm{t}$

(ii) When the time series $Y_{t}$ is increasing or decreasing by a constant percentage rather than a constant absolute amount, the logarithmic straight line time series model is used.

$\mathrm{Y}_{\mathrm{t}}=\beta_{0} \beta_{1}^{\mathrm{t}}$

or $\operatorname{Ln} Y_{t}=\operatorname{Ln} \beta_{0}+\left(\operatorname{Ln} \beta_{1}\right) \mathrm{t}$

In this case, the data plotted on a semi-logarithmic scale graph gives a straight line graph.

The approximations about the type of the curve to be fitted can be made by using the following theorem based on finite differences

"The $\mathrm{n}^{\text {th }}$ differences

$$
\Delta^{\mathrm{n}} \mathrm{Y}_{\mathrm{t}}, \Delta^{\mathrm{n}}\left(\operatorname{Ln} \mathrm{Y}_{\mathrm{t}}\right), \Delta^{\mathrm{n}}\left(\frac{1}{\mathrm{Y}_{\mathrm{t}}}\right)
$$

and $(\mathrm{n}+1)^{\text {th }}$ differences are equal to zero".

i.e., If $\Delta$ is the difference operator given by

$\Delta Y_{t}=\left[Y_{t+h}-Y_{t}\right]$, $h$ being the interval of differencing and $\Delta^{k} Y_{t}$ is the $k^{\text {th }}$ difference of $Y_{t}$ then for a polynomial $\mathrm{Y}_{\mathrm{t}}$ of $\mathrm{n}^{\text {th }}$ degree in $\mathrm{t}$, the theorem states that

$$
\begin{aligned}
\Delta^{\mathrm{k}} \mathrm{Y}_{\mathrm{t}}= & \text { constant, } \mathrm{k}=\mathrm{n} \\
=0, \mathrm{k} & >\mathrm{n}
\end{aligned}
$$

The following tests based on the calculus of finite differences may be applied in choosing approximations about the type of curve to be fitted:

(i) If $\Delta \mathrm{Y}_{\mathrm{t}}={ }_{\text {constant, then linear model }} \mathrm{Y}_{\mathrm{t}}=\beta_{0}+\beta_{1}$ t may be used;

(ii) If $\Delta^{2} \mathrm{Y}_{\mathrm{t}}=$ constant, then a second degree polynomial function model $\mathrm{Y}_{\mathrm{t}}=\beta_{0}+\beta_{1} \mathrm{t}+\beta_{2} \mathrm{t}^{2}$ may be used;

(iii) If $\Delta\left[\log \mathrm{Y}_{\mathrm{t}}\right]=$ constant, then an exponential or logarithmic linear model $\mathrm{Y}_{\mathrm{t}}=\beta_{0} \mathrm{e}^{\beta_{1} \mathrm{t}}$ or $\mathrm{Y}_{\mathrm{t}}=\beta_{0} \beta_{1}^{\mathrm{t}}$ or $\operatorname{Ln} \mathrm{Y}_{\mathrm{t}}=\operatorname{Ln} \beta_{0}+\beta_{1} \mathrm{t}$ or $\operatorname{Ln} \mathrm{Y}_{\mathrm{t}}=\operatorname{Ln} \beta_{0}+\left(\operatorname{Ln} \beta_{1}\right) \mathrm{t}$ may be used;

(iv) If $\Delta^{2}\left[\log Y_{t}\right]=$ constant, then second degree curve fitted to logarithms model

$\mathrm{Y}_{\mathrm{t}}=\beta_{0} \beta_{1}^{\mathrm{t}} \beta_{2}^{\mathrm{t}^{2}}$ or

$\operatorname{Ln} Y_{\mathrm{t}}=\operatorname{Ln} \beta_{0}+\left[\operatorname{Ln} \beta_{1}\right] \mathrm{t}+\left[\operatorname{Ln} \beta_{1}\right] \mathrm{t}^{2}$ may be used;

(v) If $\frac{\Delta \mathrm{Y}_{\mathrm{t}}}{\Delta \mathrm{Y}_{\mathrm{t}-1}}=$ constant, then a modified exponential function model $\mathrm{Y}_{\mathrm{t}}=\beta_{0}+\beta_{1} \beta_{2}^{\mathrm{t}}$ may be used;

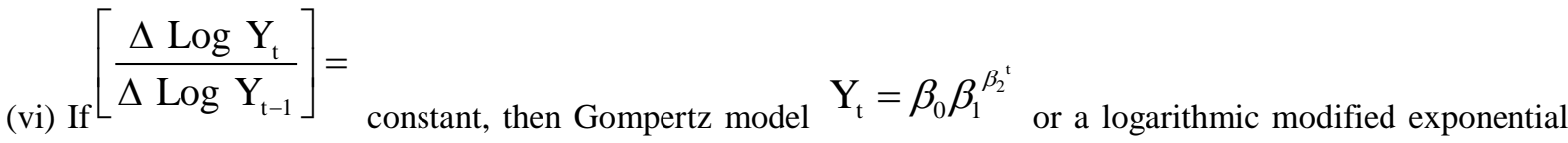
function model

$\operatorname{Ln} Y_{t}=\operatorname{Ln} \beta_{0}+\left[\operatorname{Ln} \beta_{1}\right] \beta_{2}^{\mathrm{t}}$ may be used; 
(vii) If

$$
\left[\frac{\Delta\left(1 / \mathrm{Y}_{\mathrm{t}}\right)}{\Delta\left(1 / \mathrm{Y}_{\mathrm{t}-1}\right)}\right]=
$$

$$
\mathrm{Y}_{\mathrm{t}}=\left[\frac{\mathrm{k}}{1+\mathrm{e}^{\beta_{0}+\beta_{1} \mathrm{t}}}\right], \beta_{1}<0
$$

$\frac{1}{\mathrm{Y}_{\mathrm{t}}}=\left[\frac{1}{\mathrm{k}}\right]\left[1+\mathrm{e}^{\beta_{0}+\beta_{1} \mathrm{t}}\right]$

or

where $\gamma_{0}=\frac{1}{\mathrm{k}}, \gamma_{1}=\frac{1}{\mathrm{k}} \mathrm{e}^{\beta_{0}}, \gamma_{2}=\mathrm{e}^{\beta_{1}}$ are constants

(viii) If $\Delta \mathrm{Y}_{\mathrm{t}}$ tends to decrease by a constant percentage then a modified exponential function model may be used;

(ix) If $\Delta \mathrm{Y}_{\mathrm{t}}$ shows a skewed frequency curve, then a Gompertz model or a logarithmic modified exponential function model may be used.

\section{LINEAR STATISTICAL MODEL:}

Suppose there exists a linear relationship between a dependent variable $\mathrm{Y}$ and (k-1) independent variables $\mathrm{X}_{2}$, $\mathrm{X}_{3}, \ldots \ldots, \mathrm{X}_{\mathrm{k}}$ and a random error term or disturbance term ${ }^{\varepsilon}$. For a sample of $\mathrm{n}$ observations on $\mathrm{Y}$ and $\mathrm{X}$ 's, one may specify linear regression model as

$\mathrm{Y}_{\mathrm{i}}=\beta_{1}+\beta_{2} \mathrm{X}_{2 \mathrm{i}}+\beta_{3} \mathrm{X}_{3 \mathrm{i}}+\ldots+\beta_{\mathrm{k}} \mathrm{X}_{\mathrm{ki}}+\varepsilon_{\mathrm{i}}, \mathrm{i}=1,2, \ldots, \mathrm{n}$.

where $\beta$ 's are known as regression co-efficients or unknown parameters of the linear regression model

The set of above ' $\mathrm{n}$ ' linear equations can be expressed in the matrix notation as $\mathrm{Y}_{\mathrm{nx} 1}=\mathrm{X}_{\mathrm{nxk}} \beta_{\mathrm{kx} 1}+\varepsilon_{\mathrm{nx} 1}$

$$
\mathrm{Y}=\left[\begin{array}{l}
\mathrm{Y}_{1} \\
\mathrm{Y}_{2} \\
\cdot \\
\cdot \\
\cdot \\
\mathrm{Y}_{\mathrm{n}}
\end{array}\right]_{\mathrm{nx} 1}\left[\begin{array}{ccccc}
1 & \mathrm{X}_{21} & \mathrm{X}_{31} & \ldots & \mathrm{X}_{\mathrm{k} 1} \\
1 & \mathrm{X}_{22} & \mathrm{X}_{32} & \ldots & \mathrm{X}_{\mathrm{k} 2} \\
\cdot & \cdot & \cdot & \ldots & \cdot \\
\cdot & \cdot & \cdot & \ldots & \cdot \\
\cdot & \cdot & \cdot & \ldots & \cdot \\
1 & \mathrm{X}_{2 \mathrm{n}} & \mathrm{X}_{3 \mathrm{n}} & \ldots & \mathrm{X}_{\mathrm{kn}}
\end{array}\right]_{\mathrm{nxk}} \quad \beta=\left[\begin{array}{l}
\beta_{1} \\
\beta_{2} \\
\cdot \\
\cdot \\
\cdot \\
\beta_{\mathrm{k}}
\end{array}\right]_{\mathrm{kx} 1} \quad \text { and } \varepsilon=\left[\begin{array}{l}
\varepsilon_{1} \\
\varepsilon_{2} \\
\cdot \\
\cdot \\
\cdot \\
\varepsilon_{\mathrm{n}}
\end{array}\right]_{\mathrm{nx} 1}
$$

Here, Y: (nx1) vector of observations on a random dependent random variable (observation vector)

$\mathbf{X}$ : (nxk) matrix of known observations on a set of independent variables (Data Matrix)

B: (kx1) vector of unknown parameters including intercept parameter (parametric vector)

and $\quad \mathbf{\varepsilon}:(\mathrm{nx} 1)$ vector of observations on an error random variable. (Error vector or Disturbance vector)

This model is known as a k- variable linear model or a general linear model (or linear statistical model)

\section{CRUCIAL ASSUMPTIONS OF GENERAL LINEAR MODEL}

(i) Linearity Assumption:

The basic assumption of the linear model is that the dependent variable vector or observation vector $\mathrm{Y}$ may be expressed as a linear function of the sample of observations on independent variables X's and error vector $\varepsilon_{\text {i.e., }}$ $\mathrm{Y}=\mathrm{X} \beta+\varepsilon$

\section{(ii) Unbiasedness Assumption}


$\mathrm{E}(\varepsilon)=\mathrm{O}_{\mathrm{nx} 1}$ or $\mathrm{E}(\mathrm{Y})=\mathrm{X} \beta$

where $\mathrm{O}_{\mathrm{n} \times 1}$ is $(\mathrm{n} \times 1)$ vector of zeros

$\Rightarrow \mathrm{E}\left(\varepsilon_{\mathrm{i}}\right)=0 \quad \forall \mathrm{i}=1,2, \ldots, \mathrm{n}$

$\varepsilon_{\mathrm{i}}$ are having zero means

(iii) Assumption of Homoscedastic and Uncorrelated Errors

$$
\begin{aligned}
& \mathrm{E}\left(\varepsilon \varepsilon^{\prime}\right)=\sigma^{2} \mathrm{I}_{\mathrm{n}} \\
& \begin{aligned}
\Rightarrow \operatorname{cov}\left(\varepsilon_{\mathrm{i}} \varepsilon_{\mathrm{j}}\right) & =\sigma^{2}, \forall \mathrm{i}=\mathrm{j}=1,2, \ldots \mathrm{n} \\
& =0, \forall \mathrm{i} \neq \mathrm{j}
\end{aligned}
\end{aligned}
$$

Thus, each $\varepsilon_{\mathrm{i}}$ distribution has the same unknown variance; the errors $\varepsilon_{\mathrm{i}}$ and $\varepsilon_{\mathrm{j}}, \forall \mathrm{i} \neq \mathrm{j}$ are pairwise uncorrelated.

Here, $\sigma^{2}$ is unknown error variance,

$\mathrm{I}_{\mathrm{n}}$ is an Identity matrix of order $\mathrm{n}$,i.e., $\varepsilon$ has covariance matrix $\sigma^{2} \mathrm{I}_{\mathrm{n}}$

(iv) Assumption of Linear Independence of Explanatory Variables X's:

Rank of $\mathrm{X}$ is $\mathrm{k}$, where $\mathrm{k}<\mathrm{n}$

Thus, there is no linear dependence among the Explanatory variables.

(v) Assumption of Non- Stochastic Data Matrix:

The Data matrix $\mathrm{X}$ is a non-stochastic matrix.

In other words, $\mathrm{X}$ is a fixed known coefficients matrix.

(vi) Assumption of Non- Measuremental Errors:

There are no errors involved in the explanatory variables. In other words, all the independent variables X's are measured without error. Further, $\mathrm{X}$ is uncorrelated with $\varepsilon$

\section{(vii) Normality Assumption:}

The error vector $\mathcal{E}$ follows a multivariate normal distribution with null vector $\mathrm{O}_{\mathrm{nx} 1}$ as mean vector and $\sigma^{2} \mathrm{I}_{\mathrm{n}}$ as the variance covariance matrix. Here, $\mathrm{I}_{\mathrm{n}}$ is a unit matrix of order $\mathrm{n}$.

The Linear Statistical Model along with the above crucial assumptions is known as

'Standard Linear Statistical Model'

or 'Classical Linear Statistical Model'

or 'Gauss-Markoff Linear Statistical Model'

or 'Standard General Linear Model'.

\section{ORDINARY LEAST SQUARES ESTIMATION OF PARAMETERS OF LINEAR MODEL}

Consider the Classical Linear Regression model

$$
Y_{n x 1}=X_{n x k} \beta_{k x 1}+\varepsilon_{n x 1}
$$

with usual assumptions such as

$$
E(\varepsilon)=0, E\left(\varepsilon \varepsilon^{\prime}\right)=\sigma^{2} \mathrm{I}_{n}
$$

Write the residual sum of squares as

$$
\begin{aligned}
e^{\prime} e & =(Y-X \hat{\beta})^{\prime}(Y-X \hat{\beta}) \\
& =\mathrm{Y}^{\prime} \mathrm{Y}-\hat{\hat{\beta}}^{\prime} \mathrm{X}^{\prime} \mathrm{Y}-\mathrm{Y}^{\prime} \mathrm{X} \hat{\beta}+\hat{\hat{\beta}^{\prime}} \mathrm{X}^{\prime} \mathrm{X} \hat{\beta}
\end{aligned}
$$


$\Rightarrow \mathrm{e}^{\prime} \mathrm{e}=\mathrm{Y}^{\prime} \mathrm{Y}-2 \hat{\hat{\beta}} \mathrm{X}^{\prime} \mathrm{Y}+\hat{\hat{\beta}} \mathrm{X}^{\prime} \mathrm{X} \hat{\beta} \quad\left[\because \mathrm{Y}^{\prime} \mathrm{X} \hat{\beta}=\hat{\hat{\beta}} \mathrm{X}^{\prime} \mathrm{Y}\right]$

where $\hat{\beta}$ is the least squares estimator of $\beta$

By the least squares estimation method, ${ }^{\hat{\beta}}$ minimizes the residual sum of squares $\mathrm{e}^{\prime} \mathrm{e}$.

First order condition : $\frac{\partial}{\partial \hat{\beta}}\left(\mathrm{e}^{\prime} \mathrm{e}\right)=\mathrm{O} \Rightarrow-2 \mathrm{X}^{\prime} \mathrm{Y}+2 \mathrm{X}^{\prime} \mathrm{X} \hat{\beta}=\mathrm{O}$

$$
\Rightarrow \mathrm{X}^{\prime} \mathrm{X} \hat{\beta}=\mathrm{X}^{\prime} \mathrm{Y}
$$

The system (2.7.4) contains ' $n$ ' simultaneous linear equations, which is called the 'System of Normal Equations'.

Since, the system of normal equations is always consistent, these exists atleast a non zero solution of $\hat{\beta}$, which gives the ordinary least squares (OLS) estimator of $\beta$.

i.e., $\hat{\beta}=\left(X^{\prime} X\right)^{-1} X^{\prime} Y$

Further, consider the OLS residual vector

$e=Y-X \hat{\beta}$

$=\mathrm{X} \beta+\varepsilon-\mathrm{X}\left(\mathrm{X}^{\prime} \mathrm{X}\right)^{-1} \mathrm{X}^{\prime}(\mathrm{X} \beta+\varepsilon)$

$=\varepsilon-\mathrm{X}\left(\mathrm{X}^{\prime} \mathrm{X}\right)^{-1} \mathrm{X}^{\prime} \varepsilon$

$=\left(\mathrm{I}_{\mathrm{n}}-\mathrm{X}\left(\mathrm{X}^{\prime} \mathrm{X}\right)^{-1} \mathrm{X}^{\prime}\right) \varepsilon$

$\Rightarrow e=M \varepsilon$

$\left[\mathrm{I}_{\mathrm{n}}\right.$ is a unit matrix of order $\left.\mathrm{n}\right]$

where $M=\left(I_{n}-X\left(X^{\prime} X\right)^{-1} X^{\prime}\right)$ is a symmetric idempotent matrix such that $\mathrm{M}^{\prime} \mathrm{M}=\mathrm{M}$,

$\mathrm{M}^{\prime}=\mathrm{M}$ and $\mathrm{MX}=\mathrm{O}$.

Now, consider the OLS residual sum of squares

$e^{\prime} e=(M \varepsilon)^{\prime}(M \varepsilon)=\varepsilon^{\prime} M \varepsilon$

$\Rightarrow E\left(e^{\prime} e\right)=E\left(\varepsilon^{\prime} M \varepsilon\right)$

$=E\left(\right.$ trace $\left.\varepsilon^{\prime} M \varepsilon\right)\left[\because \varepsilon^{\prime} M \varepsilon\right.$ is a scalar $]$

$=E\left(\right.$ trace $\left.M \varepsilon \varepsilon^{\prime}\right)$

$=($ trace $M) E\left(\varepsilon \varepsilon^{\prime}\right)$

$=\sigma^{2}$ trace $M \quad\left[\because E\left(\varepsilon \varepsilon^{\prime}\right)=\sigma^{2} I_{n}\right]$

$=\sigma^{2} \operatorname{trace}\left(\mathrm{I}_{\mathrm{n}}-\mathrm{X}\left(\mathrm{X}^{\prime} \mathrm{X}\right)^{-1} \mathrm{X}^{\prime}\right)$

$=\sigma^{2}\left[\operatorname{trace}_{\mathrm{n}}-\operatorname{trace}\left(\mathrm{X}^{\prime} \mathrm{X}\right)^{-1}\left(\mathrm{X}^{\prime} \mathrm{X}\right)\right]$

$=\sigma^{2}\left[n-\right.$ trace $\left.I_{k}\right]$

$\Rightarrow E\left(e^{\prime} e\right)=\sigma^{2}(n-k)$

or $E\left(\frac{e^{\prime} e}{n-k}\right)=\sigma^{2}$ 


$$
\begin{aligned}
& E\left(S^{2}\right)=\sigma^{2} \\
& S^{2}=\frac{e^{\prime} e}{n-k} \text { is an unbiased estimator of } \sigma^{2} .
\end{aligned}
$$

\section{Conclusion and Future Research}

In the above talk mathematical aspects of linear models have been extensively depicted. Different types of mathematical models are discussed here and the methods of fitting transformed models are proposed. Furthermore specific form of linear statistical model is presented and the crucial assumptions of general linear model are extensively discussed. At the last stage of this article the method of ordinary least squares estimation of parameters of a linear model has been proposed. In the context of future research one may discuss GaussMarkoff theorem for linear estimation andmean vector and covariance matrix of blue.

\section{REFERENCES}

J. Peter Praveen, R. Donthi, S.V.Prasad, B.Mahaboob, B.Venkateswarlu B., A glance on the estimation of Cobb-Douglas production functional model, AIP Conference Proceedings, 2177 (1), 020067. 2019

2. J.Peter Praveen, B. Mahaboob, R.Donthi, S.V. Prasad, B.Venkateswarlu, On stochastic linear regression model selection, AIP Conference Proceedings, 2177 (1), 020068, 2019.

3. B.Mahaboob, J.Peter Praveen, R.Donthi, S.V.Prasad, B.Venkateswarlu B., Criteria for selection of stochastic linear model selection, AIP Conference Proceedings, 2177 (1), 020041,2019.

4. R.Donthi, S.V.Prasad, B.Mahaboob, J.Peter Praveen, B.Venkateswarlu. Estimation methods of nonlinear regression models, AIP Conference Proceedings, 2177 (1), 020081, 2019.

5. R.Donthi, J.Peter Praveen, S.V.Prasad,B.Mahaboob, B.Venkateswarlu, Numerical techniques of nonlinear regression model estimation, AIP Conference Proceedings, 2177 (1), 020082. 2019.

6. B.Mahaboob, S.V.Prasad, J.Peter Praveen, R.Donthi, B.Venkateswarlu, On misspecificationtests for stochastic linear regression model,AIP Conference Proceedings, 2177 (1), 020039.2019.

7. B.Mahaboob, Ajmath K.A., Venkateswarlu B., Narayana C., Praveen J.P., On Cobb-Douglas Production function model, AIP Conference Proceedings, 2177 (1), 020040. 2019.

8. B.Mahaboob, K.A.Azmath, B.Venkateswarlu, C.Narayana, B.M.Rao An evaluation in generalized LSE of linearized stochastic statistical model with non-spherical errors, AIP Conference Proceedings, 2177(1), 020038. 2019.

9. J. Peter Praveen, B. Nageswara Rao, Y.Haranadh, B. V. Appa Rao, C. Narayana, B.

Mahaboob, Existence Of Solution Of The Nonlinear Differential Equation In The Modeling Of Eardrum By Using Homotopy Perturbation Method" Advancecs in Mathematics Scientifc journal Vol.9 (7), pp.1 - 9, 2020.

10. B. Mahaboob, J. Peter Praveen, B. V. Appa Rao, Y. Haranadh, C. Narayana, and G. Balaji Prakash, A Study On Multiple Linear Regression Using Matrix Calculus", Advancecs in Mathematics Scientifc journal, Vol.9(7), pp.1-10,2020

11. J. Peter Praveen, B. Nageswara Rao, B. Mahaboob, C. Rajaiah, Y. Harnath, And C. Narayana, "Series Decomposition Method For Asymmetric Nonlinear Oscillations", Vol.0,No.10,pp.8069-8076. (2020)

12. B. Mahaboob, K. Sreenivasulu, M. Rajaiah, Y. Harnath, C. Narayana, and J. Peter Praveen, "Jordan Generalized Derivations In Gamma Nearrings" Advancecs in Mathematics Scientifc journal,Vol.9,no.10, (2020)

13. J.Peter Praveen, B.Nageswara Rao, B.Mahaboob, B.V.Appa Rao, "An Application of Laplace Transform, Inverse Laplace Transform and Pade's Approximant in the Periodic Solution of Duffing Equation of Motion" , International Journal of Emerging Trends in Engineering Research ,Volume 8. No. 9, September 2020

14. J. Peter Praveen, B. Nageswara Rao, B.Mahaboob, M.Rajaiah, Y.Harnath, C.Narayana, "On The Simulation of Beck Column through a Simple Xiong-Wang-Tabarrok Experimental Model of Centripetally Loaded Column" International Journal of Emerging Trends in Engineering Research, Volume 8. No. 9, September 2020

15. Y.Harnath , K.Sreenivasulu , C.Narayana , B.Mahaboob , Y.Hari Krishna , G.Balaji Prakash, "An Innovative Study On Reverse Derivation In Nearrings", European Journal of Molecular \& Clinical Medicine, Volume 07, Issue 03, 2020 page:4865-4872

16. B.Mahaboob , C.Narayana , P. Sreehari Reddy , Ch. Suresh ,G.Balaji Prakash , Y. Hari Krishna , "Methods And Applications Of Linear Regression Models ",European Journal of Molecular \& Clinical Medicine , Volume 07, Issue 3, page4873-4881,2020

17.. B. Mahaboob, B. Venkateswarlu, G.S.G.N. Anjaneyulu, C. Narayana, “ A Discourse on Applications of Lie Groups and Lie Algebras" International Journal Of Scientific \& Technology Research Volume 9, Issue 02, February 2020,pp.6226-6231. 
18. B.Venkateswarlu, B. Mahaboob, K.A. Ajmath, C. Narayana, “Application of DEA in Super Efficiency Estimation" , International Journal Of Scientific \& Technology Research, Research Volume 9, Issue 02, February 2020 pp.4496-4499.

19. B. Venkateswarlu ,B. Mahaboob, C. Subbarami Reddy, C. Narayana, "Evaluating Different Types Of Efficiency Stability Regions And Their Infeasibility In DEA”, International Journal of Scientific Technology and Research, Volume 9,Issue02,February2020,Pages:3944-3949

20.B.Venkateswarlu, B. Mahaboob, C. Subbaramireddy, C. Narayana, "Multi-Criteria OptimizationTechniques in DEA: Methods \&Applications, "International Journal of Scientific Technology and Research, Volume 9, Issue02,February2020, Pages:509-515.

21. B. Mahaboob, B.Venkateswarlu, K.A. Azmath, C. Narayana, J. Peter Praveen, "On OLS Estimation of Stochastic Linear Regression Model, International Journal of Engineering and Advanced Technology, Volume-8 Issue-6,pp.1953-1955

22. B. Mahaboob, B.Venkateswarlu, C. Narayana, M. Sivaiah,” Bias In The Maximum Likelihood Estimation Of Parameters Of Nonlinear Regression Models", International Journal of Scientific \& Technology Research, Volume 8, Issue 11, November 2019 pgs:1252_1255

23.B. Venkateswarlu, B. Mahaboob, C. Narayana, C. Subbarami Reddy, "Evaluation Of Slack Based Efficiency Of A Decision Making Unit" , International Journal Of Scientific \& Technology Research, , Volume 8, Issue 11, November 2019 .Pgs:1178-1182

24. B.Venkateswarlu, B. Mahaboob, K.A. Azmath, C. Narayana, C. Muralidaran, "An Application of Linear Programming in the Estimation of Technical Efficiency of DMU", International Journal of Engineering and Advanced Technology, Volume-8 Issue-6, August, 2019,pp.1956-1959.

25. B.Venkateswarlu B. Mahaboob, C. Subbarami Reddy, C. Narayana, "New Results Production Theory By Applying Goal Programming", International Journal Of Scientific \& Technology Research, Volume 8, Issue 12, December 2019 Pgs:1918-1923

26. B. Mahaboob, B.Venkateswarlu, C. Narayana, J. Ravi sankar and P. Balasiddamuni, "A Treatise on Ordinary Least Squares Estimation of Parameters of Linear model" International Journal of Engineering and Technology, vol. 7(4.10)(2018) 518-522

27.B. Mahaboob, B.Venkateswarlu, C. Narayana, J. Ravi sankar and P. Balasiddamuni, "A Monograph on Nonlinear Regression Models”, International Journal of Engineering and Technology,vol. 7(4.10)(2018) 543546

28. B.Venkateswarlu, B. Mahaboob,J. Ravi sankar, C. Narayana and B. Madhusudhana Rao, “An Application of Goal Programming in Data Envelopment Analysis" International Journal of Engineering and Technology,vol. vol. 7(4.10)(2018) 523-525

29.C. Narayana , B. Mahaboob , B.Venkateswarlu , J. Ravi sankar, "A Memoir on Model Selection Criterion between Two Nested and Non-Nested Stochastic Nonlinear egression Models", International Journal of Engineering and Technology, vol. 7(4.10)(2018) 529-531.

30.C. Narayana, B. Mahaboob, B.Venkateswarlu, J. Ravi sankar and P. Balasiddamuni, "A Study on Misspecification and Predictive Accuracy of Stochastic Linear Regression Models", International Journal of Engineering and Technology, vol. vol. 7(4.10)(2018), 532-535.

31.C. Narayana, B. Mahaboob, B.Venkateswarlu, J. Ravi sankar and P. Balasiddamuni, "A Discourse on Modified Likelihood Ratio (LR), Wald and Lagrange Multipliers (LM) Tests for Testing General Linear Hypothesis in Stochastic Linear Regression Model", International Journal of Engineering and Technology, vol. 7(4.10)(2018) 536-538

32.C. Narayana, B. Mahaboob, B.Venkateswarlu, J. Ravi sankar and P. Balasiddamuni, "A Treatise on Testing General Linear Hypothesis in Stochastic Linear Regression Model, International Journal of Engineering and Technology, vol. 7(4.10)(2018) 539-542..

33.B Mahaboob, B Venkateswarlu and J Ravi Sankar, "Estimation of parameters of constant elasticity of substitution production functional model” IOP Conference Series: Materials Science and Engineering, 263 (2017) 042121 .

34.B Mahaboob, B Venkateswarlu, J Ravi Sankar and P Balasiddamuni, "Computation of nonlinear least squares estimator and maximum likelihood using principles in matrix calculus", IOP Conference Series: Materials Science and Engineering, 263 (2017) 042125

35.BVenkateswarlu, B Mahaboob, C Subbarami Reddy and J Ravi Sankar, "A study on technical efficiency of a DMU (review of literature) “,IOP Conference Series: Materials Science and Engineering, 263 (2017) 042124

36.B Mahaboob, B Venkateswarlu, G Mokeshrayalu and P Balasiddamuni, "New methods of testing nonlinear hypothesis using iterative NLLS estimator", IOP Conference Series: Materials Science and Engineering, 263 (2017) 042126 
37.B Venkateswarlu, B Mahaboob, C Subbarami Reddy and B MadhusudhanaRao, "Fitting of Full CobbDouglas and Full VRTS Cost Frontiers by solving Goal Programming Problem” IOP Conference Series: Materials Science and Engineering, 263 (2017) 042127

38.B Mahaboob, B Venkateswarlu2, G Mokeshrayalu and P Balasiddamuni, "A Different Approach to Estimate Nonlinear Regression Model using Numerical Methods", IOP Conference Series: Materials Science and Engineering, 263 (2017) 042122

39.K. Lakshmi, B. Mahaboob, M. Rajaiah, C. Narayana,” Ordinary least squares estimation of parameters of linear model", Journal of Mathematical and Computational Science, Vol 11 (2021), No. 2, 2015-2030 ISSN: 1927-5307

40.B. Venkateswarlu, M. Mubashir Unnissa, and B. Mahaboob” Estimating Cost Analysis using Goal Programming”, Indian Journal of Science and Technology, Vol.9(44),ISSN:0974-5645,November 2016 